\title{
Negotiating the Dominant Discourses of Explicit Instruction and Culturally Responsive Pedagogy in the Far North Queensland Context:A Teacher's Journey
}

\author{
Karen D’Aietti
}

Brian Lewthwaite

Philemon Chigeza

James Cook University

etropic 14.1 (2015): 37-43. http://www.reefandleaf.com.au/etropic.html \& http://www.jcu.edu.au/etropic

\begin{abstract}
This study took place on a remote Torres Strait (TS) island in Far North Queensland (FNQ). It focused on my teaching journey in a grade 6/7 classroom. Through an Action Research (AR) methodology the study documents my efforts to navigate and respond to two teaching models - Explicit Instruction (EI) and Culturally Responsive Pedagogy (CRP), both of which inform policy statements in the region. As well, this study highlights the tensions that arose as a result of navigating this space. Using a reflective journal, informal student dialogue sessions, yarning circles, student work samples and teacher observations, I endeavoured to adjust my practice to determine how best to meet my learners' needs, preferences and learning styles. Through on-going critical reflective practice, data collection and analysis my teaching practice underwent transformation. In addition to the critical reflective practice of my own teaching, I frequently engaged with other work colleagues, the aim of which was to both improve and transform my teaching to better serve the needs of my learners, for my overriding intention throughout this journey was not to simply accept, without question, what I was being mandated to teach, but rather to question by truly listening and responding to my students' voices (Hattie, 2012). The findings of this study strongly suggest that practitioners cannot blindly forge ahead with the EI model, but rather this model must be adjusted if practitioners are to truly consider their students from a culturally responsive viewpoint.
\end{abstract}

Keywords: Explicit Instruction; Culturally Responsive Pedagogy; Torres Strait; English as an Additional Language

\section{Introduction}

In the past decade in Australia there has been a focus on improving teacher quality in a bid to improve student learning outcomes. This focus is particularly applicable to Indigenous contexts where student outcomes have historically lagged behind the national average (Perso, 2012). As part of this initiative in improving student academic performance, many schools in FNQ are now adopting a prescriptive direct teaching methodology, Explicit Instruction, commonly referred to as EI (Queensland Government, 2008; Smith, 2001). At the same time teachers of Indigenous (both Aboriginal and Torres Strait Islander (TSI)) students are expected to teach in a way that is culturally responsive. That is, in a way that commences 
with the learner by acknowledging their backgrounds, prior experiences and knowledge and using these as a foundation upon which to cement further learning (Queensland Government, 2008). Although teachers are challenged with enacting these imperatives, how can a teacher navigate the space 'between' these two approaches? This question underscores the intent of this study.

This study took place on a remote island in the TS as a result of my problematising the mandate of teaching explicitly and, yet at the same time responding to my students in a culturally responsive manner. These factors combined, I began to critique and object to the demands placed on me to teach using solely a direct model of instruction. Was this model in the best interest of my learners who possessed rich cultural backgrounds and who spoke English as an additional language (EAL)? At the same time I began to have concerns that I was also expected to respond to my students in a culturally responsive manner. The dilemma which I faced was navigating the interface between what I considered to be two very diverse teaching methodologies. EI, on the one hand, is teacher driven, sequential and unambiguous in nature. CRP, on the other hand, positions students at the heart of learning. The teacher, adopting a variety of teaching styles, responds to the learner's needs in a responsive manner. The underlying assumption of this approach is that the learners' prior experiences, knowledge and backgrounds cannot simply be ignored, but rather used as a catalyst to promote further learning (Lewthwaite and McMillan, 2010; Lewthwaite, Owen, Doiron, McMillan and Renaud, 2013; Nakata, 2011; Osborne, 2001).

Several questions arise from within this delicate interface. How does one implement an EI model, whilst still adhering to the principles advocated for in a CRP approach? Is it indeed at all possible to intertwine these two diverse approaches and if so, what adaptions must practitioners make for this to happen? This study focused on my teaching practice over the course of one year as I navigated the space between EI and CRP. A brief literature review will be provided before outlining the theoretical framework and methodology, as well as an overview of the research's main findings.

\section{Literature Review}

The effectiveness of teaching explicitly has been widely documented in the literature (Archer and Hughes, 2011; Hollingsworth and Ybarra, 2009; Lindsay, 2012; Pearson, 2011; Rosenshine, 1987; Rowe, 2006) and indeed many schools in FNQ now require their teachers to implement an EI model in their classrooms. So what exactly is an EI approach and what does teaching in this manner actually entail? EI has been described as a "structured, systematic effective methodology for teaching academic skills" (Archer and Hughes, 2011, p. 1). Authors Hollingsworth and Ybarra (2009) describe this methodology as being well designed with age appropriate instructional techniques. Typically such lessons commence with a clear learning objective followed by a specific format commonly referred to as "I do, We do, You do". During the delivery of the lesson the teacher slowly relinquishes control until the students are ready for independent practice (You do). The pace of lessons is usually brisk, involves ample opportunities for drill and practice, as well as repetition and modelling. Such learning is based on a told curriculum; the use of data walls is actively promoted; work is typically of a written mode and assessment is rigorous and on-going (Archer and Hughes, 2011; Hollingsworth and Ybarra, 2009).

However, such a model, despite its widespread popularity, has raised concerns and has been greatly scrutinised and challenged in the literature (Gray, 1997; Kohn, 1996; Kuhn, 2007; 
Lattuca, 2006; Osborne, 2001; Sanaa, 2006). Of concern is the teacher-centred nature of this teaching style (Poplin, 1988; Steffe and Gale, 1995). Activists of constructivist approaches vehemently object to the rigid nature of teaching explicitly, advocating instead for an approach which allows the learner to discover new knowledge independently. Conversely, researcher Kohn (cited in Archer and Hughes, 2011) has critiqued the drill and practice method of learning labelling it akin to rote learning. Some consider that teaching in this manner hinders students' ability to think critically and problem-solve (Gray, 1997; Kuhn, 2007; Lattuca, 2006; Sanaa, 2006). Further, renowned culturally responsive advocate and researcher Gay (2010) sceptically questions the efficacy of direct teaching methodologies, claiming that they disregard the whole child and instead focus purely on academic achievement.

Despite such concerns, many teachers, especially those in the FNQ context, are presently mandated to teach explicitly. Practitioners faced with Indigenous students are also being required to teach in a way that is culturally responsive (Queensland Government, 2008). This in itself is a dilemma, as the two teaching models are strikingly diverse. CRP, unlike EI, places students at the centre of learning by acknowledging what it is they bring into the classroom. The curriculum is negotiated and decisions are democratic (Lewthwaite and McMillan, 2010; Lewthwaite et al., 2013; Nakata, 2011; Osborne, 2001). No longer is the teacher a figure of authority or expert, but becomes re-positioned as both facilitator and learner. The imperative in this approach is for teachers to adapt their teaching by using a variety of teaching methodologies to teach their learners who are viewed as culturally located individuals.

Practitioners advocating for culturally responsive practices, must themselves acquire a cultural knowledge base (Gay, 2010). That is, they must really understand and create strong, positive relationships with the very students they are expected to teach (Nakata, 2011). Through relevant content the learning is made interesting and appealing by embedding it within the students' cultural frames of reference. This can be achieved by valuing the whole child, adjusting the curriculum, using culturally appropriate behaviour management techniques, alternative modes of assessment, as well as ensuring that learning does not remain confined to the four walls of the classroom (Lewthwaite and McMillan, 2010; Lewthwaite et al., 2013; Nakata, 2011; Osborne, 2001; Walker, 2010).

Returning to the context of this study, I felt, as a professional, a moral obligation within me to question the status-quo of how the present educational system was operating. I was unconvinced that my EAL students being raised in a rich, cultural environment were receiving the best possible education. Unable to change the mandate imposed on me of teaching explicitly, I decided, as an alternative, to focus my energy on determining if the EI model could be adjusted to become more culturally responsive. The next section outlines the theoretical framework of the study and the methodology.

\section{Theoretical Framework and Methodology}

This study has been conducted by my overriding passion to provide my students with the best possible education by listening and responding to their voices (Hattie, 2012). The study was qualitative in nature and used data collection tools of student dialogue sessions, yarning circles and teacher observations, in addition to student work samples. In analysing the data I sought patterns to determine if there were any commonalities in how my students considered their learning. My three research questions, in brief, were: 
1. How can a teacher teach in a way that acknowledges the requirements of EI and CRP?

2. What are the guiding principles and practices that effective teachers can adopt in a Torres Strait Islander (TSI) classroom to best meet their students' needs?

3. What tensions does a teacher experience as a result of navigating this space?

This study was carried out using an Action Research (AR) methodology which is a reflective and critical enquiry into one's daily practice with the purpose of changing or improving some aspect of it (Carr and Kemmis, 1986). Through this AR project I came to view my work no longer as something I simply did, but rather as a commitment to my students. Initially, I commenced the study by documenting my concerns which were noted in my journal. Stemming from these concerns I began to engage in conversation with my students. Rather than solely relying on my own perceptions, I regularly sought contact and feedback from my principal, an experienced trusted colleague and, for issues of a culturally sensitive nature I asked my cultural mentorship team for advice. Four research cycles were used, each one building on the previous cycle. Adjustments and improvements of my practice were thus made accordingly.

The paradigm used to conduct this study was a transformative and critical one. The study was transformative in nature in that I brought about reform in my classroom. How I viewed my learners and my teaching changed over the course of the year. What is more, this study was underpinned by critical pedagogy, which compels one to look within oneself and enact change. I actively critiqued my own practice through self-reflection, mandated teacher observations and regular contact with my colleagues. Highly dissatisfied with how the TSIs had been positioned historically and continue to be positioned (Nakata, 1994), this study was above all my endeavour to bring about change in my students' lives. The next section outlines the study's findings in brief.

\section{Findings}

\section{Research Question 1:}

This study revealed that if teachers are to acknowledge the requirements of EI and CRP orientations, then the mandate to teach using an EI model cannot be taken lightly. That is, practitioners cannot blindly teach adopting this model of instruction, but must reconsider and reposition the model by adjusting their practice accordingly. Throughout the journey of this study and through reflective practice, it was discovered that teachers can adapt their practice. Some discoveries include but are not limited to reconsidering aspects of the EI model to ensure that it is delivered effectively, intertwining the I do and We do parts of the lesson with a variety of teaching activities to meet diverse learner needs, using cooperative learning, adopting alternative modes of assessment, incorporating culturally relevant content, narrative and story-telling, and by acknowledging what it is learners bring with them into the classroom.

\section{Research Question 2:}

This study revealed that an absolute imperative in teaching TSIs is that practitioners must, if they are to deliver instruction in an effective manner, listen and respond to their students. This principle should underpin all teaching and is non-negotiable if practitioners are to consider their students as culturally located individuals. In particular, the study’s findings 
revealed that adjustment of teacher practice can be attained in a variety of ways: Ask learners what they want; Adjust the EI model; Re-define success through the students' eyes; Incorporate culturally responsive practices; Use a variety of ways to help students learn; Above all, do not undermine the fact that TSIs speak EAL and consider this in every aspect of teaching.

\section{Research Question 3:}

Teachers and in particularly teachers in the TS, are bound by certain mandates placed on them at a school, College, state and national level. Such mandates result in teachers being able to adjust some but not all aspects of their practice. Throughout this journey I experienced some success in the classroom through transformation of my practice. However, with regret, I concede that not all aspects of my teaching were able to be transformed and I refer to such aspects as tensions. The outcomes of this study identified a number of on-going tensions. First and foremost, the actual level of language used in the mandated curriculum documents is of grave concern, especially considering that all TSIs possess EAL. Further, much of the content of the curriculum documents, it was discovered, is not particularly relevant to the needs of TSIs, being far removed from their cultural frames of reference. This made teaching the curriculum from a culturally responsive viewpoint challenging. What is more, sourcing alternative, more suitable content was impeded, in part, by a hectic school schedule.

Bound by the priority and emphasis to teach from the assessment task, I found deviating from assessment practices in the disciplines of maths and English virtually impossible. However, despite experiencing some success in incorporating different activities to appeal to diverse learner needs, this was impeded, in part, within the rigid boundaries of the EI model. Further, the EI model, I would strongly suggest, does not easily facilitate the inclusion of the community into learning, nor does it facilitate taking the learning outside of the classroom, both of which are deemed to be culturally responsive practices (Lewthwaite and McMillan, 2010; Lewthwaite, et al., 2013; Nakata, 2011; Osborne, 2001). Finally, I have to admit, that acquiring a cultural knowledge base will always remain an on-going challenge for nonIndigenous people and one that I personally feel will never be fully mastered in its entirety.

\section{Conclusion}

Teachers venturing to the TS must, as an imperative, listen and respond to their students' voices (Hattie, 2012). As such, they have to adapt their practice to meet their learners' needs (Lewthwaite and McMillan, 2010; Lewthwaite, et al., 2013; Nakata, 2011; Osborne, 2001). The EI model does have its merits in the classroom, but the results of this study strongly indicate that practitioners ought to proceed with caution. The model, if it is also to be viewed from a culturally responsive perspective, must be adjusted. What is more, practitioners in meeting their learners' needs must view them as culturally located individuals. This starts by acknowledging the wealth of knowledge, experiences and backgrounds of the TSIs.

Absolutely essential is that teachers recognise and respond to the fact that TSIs do not speak English as their mother-tongue but as an additional language. In teaching such students it is vital that this fact is not ignored and I would go as far as to suggest that teachers ought to receive appropriate training in this.

In reflecting on the overall study I felt that the student dialogue sessions provided some of the most valuable sources of data. Unlike the yarning circles, which took place in smaller groups and removed from the classroom, the dialogue sessions were immediate and gave students 
opportunities to interact providing a forum for discussion in a supportive environment. Teacher observations were essential to my growth as a practitioner and specific feedback enabled me to move forward in my practice, and thus meet my students' needs. Meeting with an experienced colleague allowed for thought-provoking dialogue in a non-threatening and confidential manner. Having the support of a cultural mentorship team was helpful in part, but was often difficult to arrange due to the hectic work schedule of those involved. Until aspects of the current educational system remain unchallenged and unchanged, educators in the region will always be left with unsolvable tensions. Such tensions will remain, I contend, a constant source of frustration for teachers endeavouring to teach effectively to ultimately provide their students with the best possible learning outcomes. However, in spite of such tensions, I would urge experienced teachers to consider working in this remote and culturally rich region, for on my personal journey I have discovered, through my willingness to adapt my practice and through personal critical reflection of my teaching, that the gains have far outweighed any negative issues.

\section{Disclaimer}

This article relates to the author's research towards a Doctorate in Education. This doctorate study has been approved by James Cook University and the Department of Education in Queensland. The National Statement on Ethical Conduct in Human Research has been adhered to in meeting the requirements of these approving bodies. The author is currently employed as a primary school teacher by the Department of Education. This article reflects the author's work undertaken during a three year period living in the TS as a classroom teacher. The article depicts the journey of the author and reflects the author's perceptions, not necessarily the perceptions of the Department of Education.

\section{Works Cited}

Archer, A., \& Hughes, C. (2011). Explicit Instruction. New York: London Press.

Carr, W., \& Kemmis, S. (1986). Becoming Critical. Oxen: Deakin University Press.

Gay, G. (2010). Culturally Responsive Teaching: Theory, Research and Practice. New York: Teachers College Press.

Gray, A. (1997). Constructivist Teaching and Learning. Retrieved August 20th 2012, from http://saskschoolboards.ca/research/instruction/97-07.htm

Hattie, J. (2012). Visible Learning for Teachers. Oxon, UK.: Routedge.

Hollingsworth, J., \& Ybarra, S. (2009). Explicit Direct Instruction. Thousand Oaks, California: A SAGE Company.

Kohn, A. (1996). What to look for in a Classroom. Educational Leadership, 54(1), 54-55.

Kuhn, D. (2007). Is Direct Instruction an Answer to the Right Question? Educational Psychologist, 42(2), 109-113.

Lattuca, L. R. (2006). The Constructivist Pedagogy We're Looking For. Journalism \& Mass Communication Educator, 60(4), 354-358.

Lewthwaite, B., \& McMillan, B. (2010). "She Can Bother Me, and That's Because She Cares": What Inuit Students Say About Teaching and Learning. Canadian Journal of Education, 33(1), 140-175.

Lewthwaite, B., Own, T., Doiron, A., McMillan, B., \& Renaud, R. (2013, December). Our Stories about Teaching and Learning: A Pedagogy of Consequence for Yukon First 
Nation Settings. Retrieved January 2014, from Research online JCU: www.researchonline.jcu.edu.au/30547/

Lindsay, J. (2012, July 2). What the Data Really Show: Direct Instruction Really Works! Retrieved from Direct Instruction: http://www.jefflindsay.com/EducData.shtml Nakata, M. (1994). Report on education and schooling practices in the Torres Strait and NPA regions. Thursday Island: Torres Strait Island Regional Education Committee.

Nakata, M. (2011). Pathways for Indigenous Education in the Australian Curriculum Framework. Indigenous Education, 40, 1-8.

Osborne, B. (2001). Teaching, Diversity and Democracy. Altona, Victoria: Common Ground Publishing Pty Ltd.

Pearson, N. (2011). Radical Hope: education and equality in Australia. Collingwood, Victoria: Black Inc.

Perso, T. F. (2012). Cultural Responsiveness and School Education: With particular focus on Australia's First Peoples; A Review \& Synthesis of the Literature. . Darwin: Menzies School of Health Research..

Poplin, M. (1988). Holistic/constructivist principles of the teaching/learning process: implications for the field of learning disabilities. Journal of Learning Disabilities, 21(7), 401-416.

Queensland Government, D. o. (2008). p-12 Curriculum Framework. Retrieved from http://www.education.qld.gov.au/curriculum/framework/p-12/docs/p-12/-policy.pdf

Rosenshine, B. (1987). Explicit Teaching and teacher training. Journal of Education, 38(3), 34-36.

Rowe, K. (2006). Effective teaching practices for students with and without learning difficulties: Constructivism as a legitimate theory of learning AND of teaching? Australian Journal of Learning Difficulties, 11(3), 99-115.

Sanaa, F. (2006). An Innovative, Constructivist Approach to Encourage more Independent Learning in and out of the Classroom. UGRU Journal, 2(Spring 2006), 1-6.

Smith, R. (2001). Formative Evaluation and the Scholarship of Teaching and Learning. New Directions for Teaching and Learning, 88, 51-61.

Walker, K. (2010). Deficit Thinking and the Effective Teacher. Education and Urban Society, 43(5), 576-597. 